\title{
A Surgeon's Role in the Management of Early Esophageal, EGJ and Gastric Lesions
}

\author{
Aleksandar P. Simić Ognjan M. Skrobić Predrag M. Peško \\ Department of Esophagogastric Surgery, University Hospital for Digestive Surgery, Clinical Center of Serbia, School of \\ Medicine, University of Belgrade, Belgrade, Serbia
}

\section{Keywords}

Early cancer · Esophagus · Stomach · Surgery

\begin{abstract}
Background: Endoscopic mucosal resection and submucosal dissection (ESD) are indicated in a majority of mucosal esophageal, esophagogastric junction and gastric cancers (GC), and selected cases of submucosal cancers as well. Summary: The presence of lymph node metastases in early esophageal cancer (EC) has been proven in up to $50 \%$ of patients with sm3 cancers treated with surgical resection, and up to 18.5 and $30.5 \%$ in $\mathrm{sm} 1$ and $\mathrm{sm} 2$ cancer respectively. The presence of lymphovascular invasion (LVI), tumor depth $>500 \mu \mathrm{m}$ and poor tumor differentiation seem to be a common predictor of worse outcomes in literature reports. In case of early esophagogastric junction cancer (EGJC) these predictors include LVI, tumor size $>3 \mathrm{~cm}$, Barrett's origin of the tumor and ulcerative tumor appearance. Extended indications for ESD in early GC are already adopted in high vol-
\end{abstract}

ume centers with high success rates (up to 98\%). Jet, positive resection margins after ESD, LVI and poor tumor differentiation carry high metastatic potential, therefore advocating surgery. Limited resections and cooperative laparoscopic endoscopic approach may be implemented in cases of early EGJC and GC. Key Messages: The presence of LVI, depth of submucosal invasion, and poor tumor differentiation in cases of early EC, EGJC, and GC favor surgical treatment despite improvements in endoscopic techniques.

(c) 2019 S. Karger AG, Basel

\section{Introduction}

Nowadays, we are witnessing a significant shift from surgical to endoscopic treatment of early malignant and precancerous lesions of the upper gastrointestinal tract. This shift is influenced by several factors such as enhanced endoscopic visualization and early recognition of these lesions; improved staging techniques; and advanced

\section{KARGER}

(C) 2019 S. Karger AG, Basel

E-Mail karger@karger.com

www.karger.com/ddi
Ognjan M. Skrobić

Department of Esophagogastric Surgery

University Hospital for Digestive Surgery, Clinical Center of Serbia

School of Medicine, University of Belgrade, RS-11000 Belgrade (Serbia)

E-Mail skrobico@gmail.com 
endoscopic mucosal resection (EMR) and submucosal dissection (ESD). Surgery still remains a mainstay treatment for the malignant lesions that run beyond mucosal and submucosal layers of the esophagus and stomach.

Where the indications for endoscopic treatment stop are hard to define, literature reports provide evidence for the safe use of endoscopic procedures even in cases of submucosal lesions [1,2]. However, there is plenty of evidence pointing to the primary role of surgery in patients diagnosed with early upper GI lesions. The aim of this review is to present literature data regarding the issues that define the indications for surgery as well as the modalities of surgical treatment and their outcomes in cases of early neoplasms of the esophagus, the esophagogastric junction (EGJ), and the stomach.

\section{Early Esophageal Lesions}

Lymph node (LN) metastases represent a major pathological prognostic factor for esophageal cancer (EC) survival. Proper LN staging is impossible after endoscopic resections of early esophageal lesions. Therefore, the evidence accumulated over time mainly originates from surgical reports based on histopathological evaluation of the resected specimens. These studies concentrate predominantly on the depth of submucosal invasion, tumor size, differentiation, and the presence of lymphatic invasion. Some of these reports will be outlined in this review. Manner et al. [3] published a prospective clinical study, in which they analyzed risk factors for $\mathrm{LN}$ metastases in patients with T1 sm2 and 3 cancers, treated initially with EMR followed by surgery. The overall rates of LN metastases were $21.7 \%$ in $\mathrm{T} 1 \mathrm{sm} 2$ and $35.9 \%$ in sm 3 lesions. They grouped the patients into 2 risk categories according to the tumor grade and lymphatic and venous invasion. They concluded that the frequency of LN metastases depended not so much on the depth of submucosal invasion but more on the aforementioned risk factors. However, there is still no recommendation for the endoscopic treatment of sm 2 and sm 3 ECs. In a retrospective surgical study analyzing the risk factors for lymphatic metastasis, 67 patients were identified with T1b lesions [4]. The LN metastases were observed in $22.4 \%$ of these patients, without statistical differences regarding the histological type of tumor (adenocarcinoma vs. squamocellular carcinoma). Even more importantly, the authors did not find any differences in $\mathrm{LN}$ involvement when they analyzed the depth of submucosal tumor spread, meaning that the same occurrence of LN metastases was noted in sm1, sm2 and sm3 lesions. This study outlined the significant association of the tumor size (with the cut-off value of $2 \mathrm{~cm}$ ) and the presence of lymphatic invasion with a higher probability of LN metastases. The results of a radical surgical treatment of 137 patients with T1b esophageal squamocellular carcinoma were reported by Emi et al. [5]; they found LN involvement in $18.8,30.5$, and $50 \%$ in sm1, sm2, and sm3 patients respectively. Although a significant difference between positive LN was noted between sm 1 and sm 2 patients, it did not influence the overall survival rates. In the multivariate analysis, in this study, sm3 and tumor location were strongly correlated with a worse overall survival rate. The depth of submucosal infiltration and lymphatic and venous invasion seemed to be an independent risk factor for $\mathrm{LN}$ metastases in a retrospective surgical study conducted on 295 patients with T1 esophageal squamocellular carcinoma [6]. A multicenter study that evaluated patients who were initially submitted to endoscopic resection of early esophageal adenocarcinoma (EAC) followed by esophagectomy, demonstrated that $24 \%$ of the patients with T1b tumors had positive LN [7]. The authors found that submucosal tumor depth of $>500 \mu \mathrm{m}$, the presence of lymphatic invasion, and poor tumor differentiation represented major risk factors for lymphatic spread. If all of these 3 parameters were present, LN involvement was present in $50 \%$ of the patients. What emerged as a major issue in this study was a great variability in the pathology reports analyzing the specimens obtained by ER, especially when the depth of submucosal involvement and lymphovascular invasion (LVI) had been taken into account. An expert pathologist revised $48 \%$ of the primary reports, indicating the importance of experienced high-volume center treatment.

The predictors of less favorable oncologic outcomes after endoscopic and surgical treatments of early esophageal lesions are well structured and analyzed in a systematic literature review that included 42 studies with a total of 2,092 patients, out of whom $16 \%$ had submucosal cancer [8]. The analysis showed higher LN involvement in EAC cases, and LVI was found to be the only predictor of LN metastases. The study implicated that even patients with sml submucosal cancer should be treated with esophagectomy and lymphadenectomy due to increased risk of LN metastases. It was even suggested that patients with negative predictors such as grade $3, \mathrm{sm} 3$ and LVI may benefit from multimodal treatment, preferably neoadjuvant chemotherapy or chemoradiotherapy. Another study pointed out that LVI showed to be a major determinant in cancers invading the muscularis mucosae, because when it was present, the cumulative 5-year meta- 
Fig. 1. Early EC algorithm, including extended indications for esophageal submucosal dissection. EC, esophageal cancer; $\mathrm{MR}$, mucosal resection; ESD, endoscopic submucosal dissection; LVI, lymphovascular invasion.



static rates were significantly higher (46.7 vs. $0.7 \%$ ) [9]. These data support the fact that a specimen obtained by ER or ESD must be submitted for detailed examination by a dedicated pathologist in order to address all the aforementioned factors, which could subsequently lead to adjustments in the approach to patients with early EC.

What emerges as a common conclusion in all of the analyzed studies is the fact that T1b EC is still an indication for radical surgery, especially in those patients with a tumor size of $>2 \mathrm{~cm}$, depth of submucosal invasion of $>500 \mu \mathrm{m}$, poor differentiation, and the presence of LVI. LVI in patients with cancer limited to mucosa also carries severe metastatic potential, therefore favoring a surgical approach (Fig. 1).

Different surgical approaches for treating early EC were proposed. Still, most literature reports focus on radical esophagectomy with gastric pull-up reconstruction, basically the Ivor Lewis procedure for distal cancer, especially in EAC cases, and the McKeown procedure in cases of SCC. Stein et al. $[10,11]$ proposed transhiatal resection of distal esophagus and jejunal interposition according to Merendino as an alternative to more invasive surgical options, favoring this approach because it allows the preservation of a larger part of the stomach and improved quality of life for these patients. The rationale for this kind of approach in early EAC comes from the fact that the lymphatic spread in early EAC starts later, and it is most often restricted to the locoregional nodes, which is not the case in early SCC [11].

Another specific role of surgery in the treatment of precancerous and early EAC may be the addition of the antireflux surgery after the endoscopic treatment of these lesions. There are literature reports justifying laparoscopic antireflux surgery after radiofrequency ablation of Barrett's esophagus (BE), as it has been proven that the addition of fundoplication may result in less persistent or recurrent $\mathrm{BE}$, especially in patients with longer $\mathrm{BE}$ segments and a hiatal hernia of $>3 \mathrm{~cm}[12,13]$. Future studies in this direction are certainly warranted.

\section{Early EGJ Lesions}

EGJ represents a truly dynamic anatomic and histologic region, in which esophageal strongly interacts with gastric pathology. This is the region where we have to recognize different types of epithelium, such as oxintocardiac and cardiac mucosa as well as intestinal metaplasia of esophagus, or BE. Cancers at the level of cardia seem to have more aggressive clinical behavior than those originating at stomach level. Patients with cardia cancer are more often presented with LN metastases, and tend to have poorer survival rates and more hematological tumor 
spreading compared to patients with stomach cancer of other locations [14]. For the purpose of this review, we decided to follow the Siewert classification, which still seems to be a useful clinical guide for the treatment of the EGJ lesions, despite all its limitations [15]. We focus upon Siewert type II tumors, which are considered to be the socalled true cardia carcinomas, while type I and III belong to the esophagus and stomach respectively. What may be of relevance is the fact that, in this anatomic region, one can identify 2 different histopathological forms of tumors: Barrett's esophagus adenocarcinoma (BEA) and gastric cardia adenocarcinoma (GCA).

Nunobe et al. [16] were the first to analyze Siewert type II BEA and GCA, and show that these tumors differ significantly in terms of clinical behavior and histopathology. They also showed that GCA might grow underneath the squamous epithelium, which makes its treatment and classification more difficult. Osumi et al. [17] also reported the results following the ESD for Siewert type II BEA and GCA, showing that in cases of BEA the curative resection rate was significantly lower than that in the GCA cases. Furthermore, the percent of lesions that invade deeper than sm2 and are present with LVI were statistically significantly higher in the Siewert type II BEA. A higher rate of lymphatic invasion in BEA EGJ cases may be explained by the fact that lymphatic vessel density is higher in BE than it is in the stomach [18]. The presence of lymphatic invasion represents an independent prognostic factor for LN metastasis; therefore, patients with BEA and lymphatic invasion at the EGJ level may benefit from surgical approach significantly more than those with GCA.

By knowing that cardia cancers are more aggressive in terms of early lymphatic spread, there is a question whether the indications for submucosal dissection of early stomach cancer may be applied in the case of cardia cancer. Pyo et al. [19] analyzed the patterns and rates of LN metastases, as well as the other risk factors, in patients with early Siewert type II and III cancers that underwent radical surgery. The authors found that patients with $\mathrm{sm} 1$ cancers, classified by submucosal invasion of $<500 \mu \mathrm{m}$, and tumors smaller than $3 \mathrm{~cm}$ had no LN metastases. However, with deep submucosal invasion of $\geq 500 \mu \mathrm{m}$ classified as sm 2 and sm 3 , the incidence of LN metastases was $28.6 \%$, regardless of the tumor size. These findings implicate that even patients with sm 1 and less than $3 \mathrm{~cm}$ in diameter may be safely treated with ESD, which is beyond the proposed guidelines, suggesting that differentiated mucosal cancer without ulceration and smaller than $2 \mathrm{~cm}$ may be safely treated with ESD [20]. The long-term comparative results of ESD and surgery for early EGJ cancer Siewert type II were the subject of the analysis published by Kim et al. [21]. The indications for ESD included intramucosal well-differentiated tumors with ulceration of $<3 \mathrm{~cm}$, without ulceration of any size, welldifferentiated submucosal $\mathrm{sm} 1$ tumors sized $<3 \mathrm{~cm}$, and poorly differentiated intramucosal tumors with ulceration of $<2 \mathrm{~cm}$ in size. Patients who were submitted to surgery were operated with total gastrectomy, and $\mathrm{D} 1+\beta \mathrm{LN}$ dissection. Although patients who were submitted to surgery were younger and with lesions that were larger in diameter, more commonly presented as flat or depressed, the overall survival and 5-year disease-free survival rates did not significantly differ between the 2 groups. Yet, 4 patients out of 38 had a recurrence in the ESD group, and 1 at the level of esophago-jejunal anastomosis in the surgical group. There was no statistical significance regarding the recurrence, but there was an obvious inclination among the physicians toward surgery in younger patients with larger and flat- appearing early lesions of the cardia (Fig. 2).

The surgical options for the treatment of early EGJ lesions mainly depend upon surgical preference. There are several options that could be implemented, starting from total gastrectomy with distal esophagectomy and Rouxen-Y reconstruction, distal esophagectomy, and proximal gastrectomy with gastric pull-up or jejunal interposition. In cases of early EGJ cancers, Siewert type II, sufficient LN dissection may be obtained via all the above-mentioned approaches [22-24]. Both esophagectomy and total gastrectomy seem to have equal outcomes when it comes to negative surgical margins rate, the number of harvested $\mathrm{LN}$, and 5-year overall survival rates for Siewert type II cancer [25]. In the case of early EGJ lesions, surgical treatment must not be tailored only based on the oncologic outcome, but it must also aid the preservation of the digestive function as much as possible. Several authors published their favorable functional results on proximal gastrectomy and double tract jejunal reconstruction [26,27].

To summarize, surgery is the mainstay treatment option in EGJ cancer invading submucosa, especially in cases of ulcerative and flat lesions. EGJ cancer of BE origin is more aggressive than the one originating from the stomach, and such patients may benefit from surgery. Extended indications for ESD in the early lesions of cardia may be implemented in experienced centers, with outcomes that are similar to surgical outcomes, yet they are still more often implemented in older patients with favorable macroscopic tumor appearance for endoscopic treatment. 
Fig. 2. Early EGJC algorithm, including extended indications for esophageal submucosal dissection. EGJC, esophagogastric junction cancer; $\mathrm{MR}$, mucosal resection; ESD, endoscopic submucosal dissection.

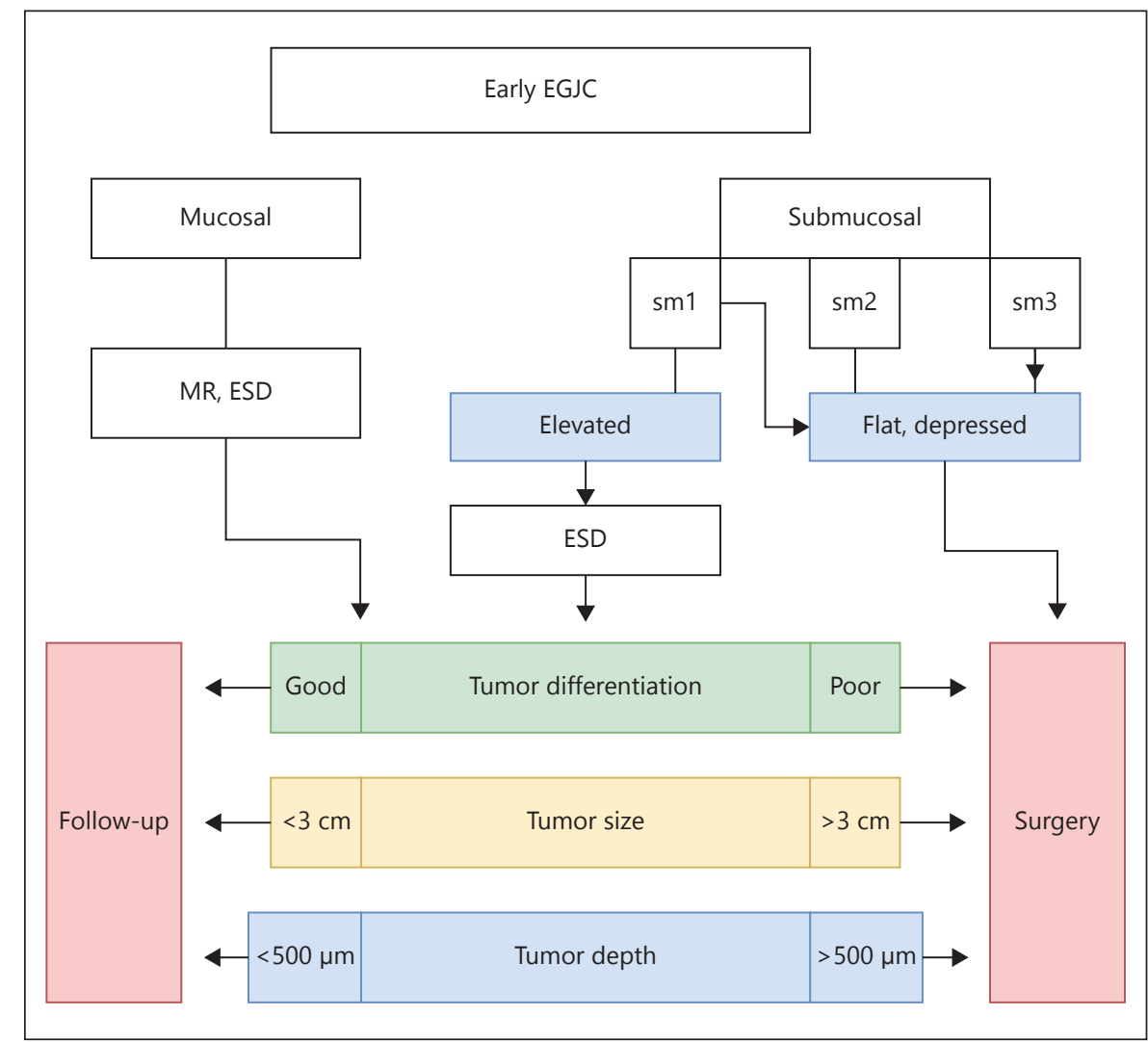

\section{Early Gastric Lesions}

Early gastric cancer (EGC) accounts for $15-57 \%$ of the incidentally discovered gastric carcinoma. Variations in incidence are mostly due to different geographic regions and the use of screening programs. Because of the widespread use of screening, it is most frequently reported in Japan $[28,29]$. However, the number of EGC is repeatedly rising in other parts of the world [30,31]. EGC as an entity was first defined in 1971 by the Japanese Society of Gastroenterology and Endoscopy [5] as a lesion limited to mucosa, with or without submucosa, regardless of the lymphnode status [28, 32].

It has been established that the spreading of malignant tissue in the submucosa is associated with an increase in the incidence of metastasis in regional LN and, therefore, a poor outcome prognosis $[28,33,34]$. There is a very high prevalence of affected LN in cases of LVI, poor differentiation [35-38] and in the diffuse type of adenocarcinoma with a size of $>2 \mathrm{~cm}$ [39-41]. In the case of verified LN metastasis, surgery and chemotherapy in the adjuvant setting represent the treatment of choice [42]. The incidence of LN metastases in EGC is very low; it is estimated to be around $3 \%$ in the case of mucosal tumors, rising to nearly $20 \%$ when submucosa is invaded [43]. Overall, the EGC has a good prognosis, with a 5-year survival rate of over $90 \%$ [44].

Endoscopic therapy is intended for patients with diagnosed EGC and no risk of LN involvement. Among other advantages, endoscopic resection enables the pathologist to predict the risk of LN metastasis by assessing the depth of invasion, degree of differentiation, and lymphovascular involvement. The "standard" criteria for endoscopic treatment include the intestinal type of adenocarcinoma limited to mucosa, lesions of $<20 \mathrm{~mm}$ without ulceration, or of $<10 \mathrm{~mm}$ for flat and depressed lesions $[45,46]$. However, we need to mention the newly given extended criteria, which include the intestinal type adenocarcinoma confined to mucosa of any size but without ulceration, of $<3 \mathrm{~cm}$ in diameter with ulceration, EGC of intestinal type confined to upper $0.5 \mathrm{~mm}$ of submucosa, or non-ulcerated EGC of any type of $<2 \mathrm{~cm}[47,48]$ (Fig. 3).

EMR is considered to be a highly effective and safe treatment for superficial lesions; however, it requires specific endoscopic experience due to possible complications. Different studies have shown excellent results using EMR, ranging from a 5-year survival rate greater than $85-90 \%[49,50]$ and a risk of recurrence rate below $35 \%$ 
Fig. 3. EGC algorithm, including extended indications for esophageal submucosal dissection. EGC, early gastric cancer; MR, mucosal resection; ESD, endoscopic submucosal dissection; UL, ulceration.

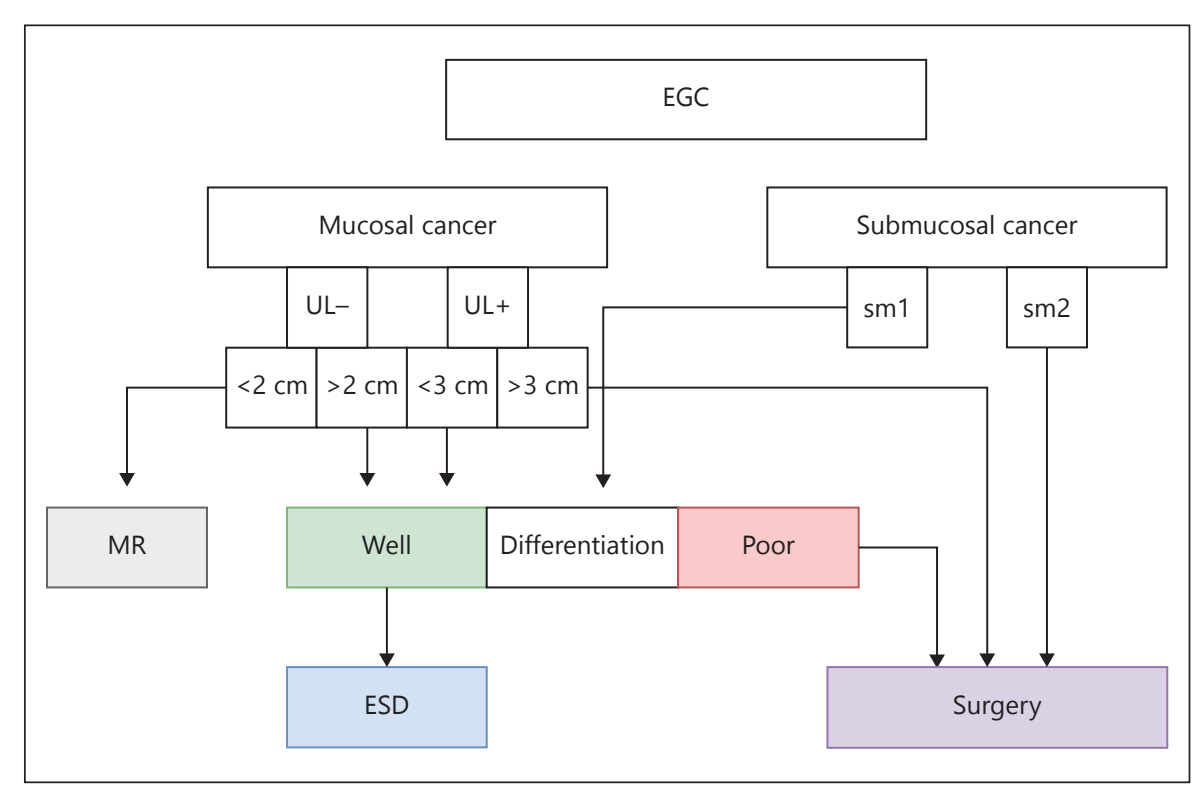

to practically nonexistent in the case of en bloc resection. However, in few cases when incomplete resection is performed and resection margins are positive for infiltration, gastrectomy might be indicated [51-53]. Stage IB (T1N1) should be treated with total or modified gastric resection, whereas stage II tumors require standard gastrectomy independent of other parameters [54, 55].

Endoscopic submucosal resection (ESD) is a procedure reserved for larger EGC, which avoids piecemeal resection of EMR and possibly diminishes the risk of recurrence, while allowing for more reproducible and higher quality pathological specimens. The indications for ESD are similar to EMR $[56,57]$. This is a demanding procedure, which should be performed by skillful endoscopists, and it requires a long learning curve [58-61]. The success rates for ESD are between 95 and $98 \%$ for en bloc resection and a 5-year survival rate of $83-97 \%[62,63]$. In cases when resection with ESD is incomplete (positive resection margins, invasion of the submucosa or muscularis, LVI, or undifferentiated cancer), surgery should be considered (gastrectomy with perigastric nodal resection) [64]. Lee et al. [65] analyzed the long-term outcomes of ESD and surgery for EGC, employing expanded indications, which were mentioned above. There were no significant differences regarding the overall survival and disease survival rates between the groups (5-year OS rates were $98.1 \%$ in the ESD group and $96.4 \%$ in the surgery group). However, the recurrence free survival was lower in the ESD group. Metachronous recurrences comprised $84.4 \%$ of all the recurrences in the ESD group, while extragastric recurrences were the most common type in the surgical group. The majority of recurrences in the ESD group were treated with salvage submucosal dissection with an $88.9 \%$ success rate.

Even though EMR and ESD continually show high success rates, total or subtotal gastrectomy with D2 LNs dissection still seems to be widely recommended. These points of view are supported by 2 observations: first, D2 LNs are occasionally involved when the tumor is extended to submucosa; second, as aforesaid, tumors routinely classified as N0 are sometimes understaged as micrometastases could be detected at IHC in up to $50 \%$ of the cases $[66,67]$. Besides total and subtotal gastrectomy with radical LN dissection, in the case of EGC, the so-called function-preserving gastrectomies, such as proximal gastrectomy, pylorus preserving gastrectomy, or local gastric resection, may be implemented. There is evidence that pylorus-preserving gastrectomy may result in a lower incidence of postgastrectomy dumping syndrome than a typical distal gastrectomy with Billroth I reconstruction. [68] Lower incidence of dumping, less diarrhea, and body weight preservation were reported when proximal gastrectomy was compared with total gastrectomy [69]. Yet, there is no evidence to support these procedures in everyday clinical practice. As for local or limited gastric resection in the case of EGC, the majority of these indications are nowadays covered with endoscopic treatment. This procedure could have advantage over total gastrectomy with accurate sentinel LN mapping, as the majority of EGC cases are still classified as N0 [70].

Laparoscopic and endoscopic cooperative surgery may also have a role in the treatment of EGC, especially 
in those cases with lateral cancer spreading or intramucosal tumors with adjacent ulcer scars [71-73]. In the future, close collaboration between endoscopists and surgeons, reflected in laparoscopic and endoscopic cooperative surgery for example, could bring more advances in the treatment of EGC, with the effort to preserve the affected organ as much as possible without compromising oncologic outcomes.

\section{Statement of Ethics}

The authors have no ethical conflicts to disclose.

\section{Disclosure Statement}

The authors declare that they have no conflicts of interest to disclose.

\section{References}

1 Manner H, Pech O, Heldmann Y, May A, Pohl J, Behrens A, et al. Efficacy, safety, and long-term results of endoscopic treatment for early stage adenocarcinoma of the esophagus with low-risk sm1 invasion. Clin Gastroenterol Hepatol. 2013 Jun;11(6):630-5.

2 Manner H, Pech O, Heldmann Y, May A, Pauthner M, Lorenz D, et al. The frequency of lymph node metastasis in early-stage adenocarcinoma of the esophagus with incipient submucosal invasion (pT1b sm1) depending on histological risk patterns. Surg Endosc. 2015 Jul;29(7):1888-96.

3 Manner H, Wetzka J, May A, Pauthner M, Pech O, Fisseler-Eckhoff A, et al. Early-stage adenocarcinoma of the esophagus with mid to deep submucosal invasion (pT1b sm2-3): the frequency of lymph-node metastasis depends on macroscopic and histological risk patterns. Dis Esophagus. 2017 Feb;30(3):1-11.

4 Nentwich MF, von Loga K, Reeh M, Uzunoglu FG, Marx A, Izbicki JR, et al. Depth of submucosal tumor infiltration and its relevance in lymphatic metastasis formation for $\mathrm{T} 1 \mathrm{~b}$ squamous cell and adenocarcinomas of the esophagus. J Gastrointest Surg. 2014 Feb; 18(2):242-9.

5 Emi M, Hihara J, Hamai Y, Furukawa T, Ibuki Y, Okada M. Clinicopathologic features of submucosal esophageal squamous cell carcinoma. Ann Thorac Surg. 2017 Dec;104(6): 1858-64.

6 Akutsu Y, Uesato M, Shuto K, Kono T, Hoshino I, Horibe D, et al. The overall prevalence of metastasis in T1 esophageal squamous cell carcinoma: a retrospective analysis of 295 patients. Ann Surg. 2013 Jun;257(6):1032-8.

7 Boys JA, Worrell SG, Chandrasoma P, Vallone JG, Maru DM, Zhang L, et al. Can the risk of lymph node metastases be gauged in endoscopically resected submucosal esophageal adenocarcinomas? A multi-center study. J Gastrointest Surg. 2016 Jan;20(1):6-12.

8 Sgourakis G, Gockel I, Lang H. Endoscopic and surgical resection of $\mathrm{T} 1 \mathrm{a} / \mathrm{T} 1 \mathrm{~b}$ esophageal neoplasms: a systematic review. World J Gastroenterol. 2013 Mar;19(9):1424-37.

9 Yamashina T, Ishihara R, Nagai K, Matsuura $\mathrm{N}$, Matsui $\mathrm{F}$, Ito $\mathrm{T}$, et al. Long-term outcome and metastatic risk after endoscopic resection of superficial esophageal squamous cell carci- noma. Am J Gastroenterol. 2013 Apr;108(4): 544-51.

10 Stein HJ, Feith M, Mueller J, Werner M, Siewert JR. Limited resection for early adenocarcinoma in Barrett's esophagus. Ann Surg. 2000 Dec;232(6):733-42.

11 Stein HJ, Feith M, Bruecher BL, Naehrig J, Sarbia M, Siewert JR. Early esophageal cancer: pattern of lymphatic spread and prognostic factors for long-term survival after surgical resection. Ann Surg. 2005 Oct;242(4):566-73.

12 Skrobić $\mathrm{O}$, Simić A, Radovanović N, Ivanović N, Micev M, Peško P. Significance of Nissen fundoplication after endoscopic radiofrequency ablation of Barrett's esophagus. Surg Endosc. 2016 Sep;30(9):3802-7.

13 O'Connell K, Velanovich V. Effects of Nissen fundoplication on endoscopic endoluminal radiofrequency ablation of Barrett's esophagus. Surg Endosc. 2011 Mar;25(3):830-4.

14 Saito H, Fukumoto Y, Osaki T, Fukuda K, Tatebe S, Tsujitani S, et al. Distinct recurrence pattern and outcome of adenocarcinoma of the gastric cardia in comparison with carcinoma of other regions of the stomach. World J Surg. 2006 Oct;30(10):1864-9.

15 Siewert JR, Stein HJ. Classification of adenocarcinoma of the oesophagogastric junction. Br J Surg. 1998 Nov;85(11):1457-9.

16 Nunobe S, Nakanishi Y, Taniguchi H, Sasako M, Sano T, Kato H, et al. Two distinct pathways of tumorigenesis of adenocarcinomas of the esophagogastric junction, related or unrelated to intestinal metaplasia. Pathol Int. 2007 Jun;57(6):315-21.

17 Osumi H, Fujisaki J, Omae M, Shimizu T, Yoshio $\mathrm{T}$, Ishiyama A, et al. Clinicopathological features of Siewert type II adenocarcinoma: comparison of gastric cardia adenocarcinoma and Barrett's esophageal adenocarcinoma following endoscopic submucosal dissection. Gastric Cancer. 2017 Jul;20(4):663-70.

18 Brundler MA, Harrison JA, de Saussure B, de Perrot M, Pepper MS. Lymphatic vessel density in the neoplastic progression of Barrett's oesophagus to adenocarcinoma. J Clin Pathol. 2006 Feb;59(2):191-5.

19 Pyo JH, Lee H, Min YW, Min BH, Lee JH, Kim $\mathrm{KM}$, et al. Indication for endoscopic treatment based on the risk of lymph node metastasis in patients with Siewert type II/III early gastric cancer. Gastric Cancer. 2018 Jul;21(4): 672-9.

20 Japanese Gastric Cancer Association. Japanese gastric cancer treatment guidelines 2014 (ver. 4). Gastric Cancer. 2017 Jan;20(1):1-19.

21 Kim HJ, Chung H, Shin SK, Kim HI, Park JC, Lee SK, et al. Comparison of long-term clinical outcomes between endoscopic and surgical resection for early-stage adenocarcinoma of the esophagogastric junction. Surg Endosc. 2018 Aug;32(8):3540-7.

22 Hashimoto T, Kurokawa Y, Mori M, Doki Y. Surgical Treatment of Gastroesophageal Junction Cancer. J Gastric Cancer. 2018 Sep; 18(3):209-17.

23 Amenabar A, Hoppo T, Jobe BA. Surgical management of gastroesophageal junction tumors. Semin Radiat Oncol. 2013 Jan;23(1): 16-23.

24 Yabusaki H, Nashimoto A, Matsuki A, Aizawa $M$. Comparison of the surgical treatment strategies for Siewert type II squamous cell carcinoma in the same area as esophagogastric junction carcinoma: data from a single Japanese high-volume cancer center. Surg Today. 2014 Aug;44(8):1522-8.

25 Kauppila JH, Wahlin K, Lagergren J. Gastrectomy compared to oesophagectomy for Siewert II and III gastro-oesophageal junctional cancer in relation to resection margins, lymphadenectomy and survival. Sci Rep. 2017 Dec;7(1):17783.

26 Nomura E, Lee SW, Kawai M, Yamazaki M, Nabeshima K, Nakamura K, et al. Functional outcomes by reconstruction technique following laparoscopic proximal gastrectomy for gastric cancer: double tract versus jejunal interposition. World J Surg Oncol. 2014 Jan; 12(1):20.

27 Xiao JW, Liu ZL, Ye PC, Luo YJ, Fu ZM, Zou $\mathrm{Q}$, et al. Clinical comparison of antrum-preserving double tract reconstruction vs rouxen-Y reconstruction after gastrectomy for Siewert types II and III adenocarcinoma of the esophagogastric junction. World J Gastroenterol. 2015 Sep;21(34):9999-10007.

28 Green PH, O'Toole KM, Slonim D, Wang T, Weg A. Increasing incidence and excellent survival of patients with early gastric cancer: experience in a United States medical center. Am J Med. 1988 Nov;85(5):658-61. 
29 Rokkas T, Filipe MI, Sladen GE. Detection of an increased incidence of early gastric cancer in patients with intestinal metaplasia type III who are closely followed up. Gut. 1991 Oct; 32(10):1110-3

30 Correa P, Piazuelo MB, Wilson KT. Pathology of gastric intestinal metaplasia: clinical implications. Am J Gastroenterol. 2010 Mar; 105(3):493-8.

31 Dinis-Ribeiro M, Areia M, de Vries AC, Marcos-Pinto R, Monteiro-Soares M, O'Connor A, et al.; European Society of Gastrointestinal Endoscopy; European Helicobacter Study Group; European Society of Pathology; Sociedade Portuguesa de Endoscopia Digestiva. Management of precancerous conditions and lesions in the stomach (MAPS): guideline from the European Society of Gastrointestinal Endoscopy (ESGE), European Helicobacter Study Group (EHSG), European Society of Pathology (ESP), and the Sociedade Portuguesa de Endoscopia Digestiva (SPED). Endoscopy. 2012 Jan;44(1):74-94.

32 Japanese Research Society for Gastric Cancer Japanese classification of gastric carcinoma. Tokyo: Kanehara \& Co., Ltd.; 1995.

33 Sano T, Sasako M, Kinoshita T, Maruyama K. Recurrence of early gastric cancer. Follow-up of 1475 patients and review of the Japanese literature. Cancer. 1993 Dec;72(11):3174-8.

34 Murakami T. Pathomorphological diagnosis, definition and gross classification of early gastric cancer. Gann Monogr Cancer Res. 1971; 11:53-5.

35 Folli S, Morgagni P, Roviello F, De Manzoni G, Marrelli D, Saragoni L, et al.; Italian Research Group for Gastric Cancer (IRGGC). Risk factors for lymph node metastases and their prognostic significance in early gastric cancer (EGC) for the Italian Research Group for Gastric Cancer (IRGGC). Jpn J Clin Oncol. 2001 Oct;31(10):495-9.

36 Popiela T, Kulig J, Kolodziejczyk P, Sierzega M; Polish Gastric Cancer Study Group. Longterm results of surgery for early gastric cancer. Br J Surg. 2002 Aug;89(8):1035-42.

37 Degiuli M, Calvo F. Survival of early gastric cancer in a specialized European center. Which lymphadenectomy is necessary? World J Surg. 2006 Dec;30(12):2193-203.

38 Gertler R, Stein HJ, Schuster T, Rondak IC, Höfler H, Feith M. Prevalence and topography of lymph node metastases in early esophageal and gastric cancer. Ann Surg. 2014 Jan; 259(1):96-101.

39 Son HJ, Song SY, Kim S, Noh JH, Sohn TS, Kim DS, et al. Characteristics of submucosal gastric carcinoma with lymph node metastatic disease. Histopathology. 2005 Feb;46(2): 158-65.

40 Song SY, Park S, Kim S, Son HJ, Rhee JC. Characteristics of intramucosal gastric carcinoma with lymph node metastatic disease. Histopathology. 2004 May;44(5):437-44.

41 Ohashi S, Okamura S, Urano F, Maeda M. Clinicopathological variables associated with lymph node metastasis in submucosal inva- sive gastric cancer. Gastric Cancer. 2007; 10(4):241-50.

42 Waddell T, Verheij M, Allum W, Cunningham D, Cervantes A, Arnold D; European Society for Medical Oncology (ESMO); European Society of Surgical Oncology (ESSO); European Society of Radiotherapy and Oncology (ESTRO). Gastric cancer: ESMO-ESSO-ESTRO Clinical Practice Guidelines for diagnosis, treatment and follow-up. Ann Oncol. 2013 Oct;24(24 Suppl 6):vi57-63.

43 Fernández-Esparrach G, Calderón Á, De-laPeña J, Díaz-Tasende JB, Esteban JM, Gimeno-García AZ, et al.; Sociedad Española de Endoscopia Digestiva (SEED). Endoscopic submucosal dissection. Sociedad Española de Endoscopia Digestiva (SEED) clinical guideline. Rev Esp Enferm Dig. 2014 Feb;106(2): $120-32$.

44 Ono H, Kondo H, Gotoda T, Shirao K, Yamaguchi H, Saito D, et al. Endoscopic mucosal resection for treatment of early gastric cancer. Gut. 2001 Feb;48(2):225-9.

45 Min YW, Min BH, Lee JH, Kim JJ. Endoscopic treatment for early gastric cancer. World J Gastroenterol. 2014 Apr;20(16):4566-73.

46 Soetikno R, Kaltenbach T, Yeh R, Gotoda T. Endoscopic mucosal resection for early cancers of the upper gastrointestinal tract. J Clin Oncol. 2005 Jul;23(20):4490-8.

47 Ahn JY, Jung HY, Choi KD, Choi JY, Kim MY, Lee JH, et al. Endoscopic and oncologic outcomes after endoscopic resection for early gastric cancer: 1370 cases of absolute and extended indications. Gastrointest Endosc. 2011 Sep;74(3):485-93.

48 Kang HJ, Kim DH, Jeon TY, Lee SH, Shin N, Chae SH, et al. Lymph node metastasis from intestinal-type early gastric cancer: experience in a single institution and reassessment of the extended criteria for endoscopic submucosal dissection. Gastrointest Endosc. 2010 Sep;72(3):508-15.

49 Takekoshi T, Baba Y, Ota H, Kato Y, Yanagisawa A, Takagi K, et al. Endoscopic resection of early gastric carcinoma: results of a retrospective analysis of 308 cases. Endoscopy. 1994 May;26(4):352-8.

50 Uedo N, Iishi H, Tatsuta M, Ishihara R, Higashino $\mathrm{K}$, Takeuchi $\mathrm{Y}$, et al. Longterm outcomes after endoscopic mucosal resection for early gastric cancer. Gastric Cancer. 2006; 9(2):88-92.

51 Kojima T, Parra-Blanco A, Takahashi H, Fujita R. Outcome of endoscopic mucosal resection for early gastric cancer: review of the Japanese literature. Gastrointest Endosc. 1998 Nov;48(5):550-4.

52 Ahn JY, Jung HY, Choi JY, Kim MY, Lee JH, Choi KS, etal. Natural course of noncurativeendoscopicresection of differentiated earlygastric cancer. Endoscopy. 2012 Dec;44(12):1114-20.

53 Nagano H, Ohyama S, Fukunaga T, Seto Y, Fujisaki J, Yamaguchi T, et al. Indications for gastrectomy after incomplete EMR for early gastric cancer. Gastric Cancer. 2005;8(3): 149-54.
54 Nakajima T. Gastric cancer treatment guidelines in Japan. Gastric Cancer. 2002;5(1):1-5.

55 Ishikawa S, Togashi A, Inoue M, Honda S, Nozawa F, Toyama E, et al. Indications for EMR/ESD in cases of early gastric cancer: relationship between histological type, depth of wall invasion, and lymph node metastasis. Gastric Cancer. 2007;10(1):35-8.

56 Oka S, Tanaka S, Kaneko I, Mouri R, Hirata M, Kawamura T, et al. Advantage of endoscopic submucosal dissection compared with EMR for early gastric cancer. Gastrointest Endosc. 2006 Dec;64(6):877-83.

57 Probst A, Pommer B, Golger D, Anthuber M, Arnholdt H, Messmann H. Endoscopic submucosal dissection in gastric neoplasia - experience from a European center. Endoscopy. 2010 Dec;42(12):1037-44.

58 Oda I, Odagaki T, Suzuki H, Nonaka S, Yoshinaga $S$. Learning curve for endoscopic submucosal dissection of early gastric cancer based on trainee experience. Dig Endosc. 2012 May;24 Suppl 1:129-32.

59 Dinis-Ribeiro M, Pimentel-Nunes P, Afonso M, Costa N, Lopes C, Moreira-Dias L. A European case series of endoscopic submucosal dissection for gastric superficial lesions. Gastrointest Endosc. 2009 Feb;69(2):350-5.

60 Deprez PH, Bergman JJ, Meisner S, Ponchon T, Repici A, Dinis-Ribeiro M, et al. Current practice with endoscopic submucosal dissection in Europe: position statement from a panel of experts. Endoscopy. 2010 Oct;42(10): 853-8.

61 Vázquez-Sequeiros E, de Miquel DB, Olcina JR, Martín JA, García M, Lucas DJ, et al. Training model for teaching endoscopic submucosal dissection of gastric tumors. Rev Esp Enferm Dig. 2009 Aug;101(8):546-52.

62 Chung IK, Lee JH, Lee SH, Kim SJ, Cho JY, Cho WY, et al. Therapeutic outcomes in 1000 cases of endoscopic submucosal dissection for early gastric neoplasms: korean ESD Study Group multicenter study. Gastrointest Endosc. 2009 Jun;69(7):1228-35.

63 Kosaka T, Endo M, Toya Y, Abiko Y, Kudara $\mathrm{N}$, Inomata $\mathrm{M}$, et al. Long-term outcomes of endoscopic submucosal dissection for early gastric cancer: a single-center retrospective study. Dig Endosc. 2014 Mar;26(2):183-91.

64 Jung H, Bae JM, Choi MG, Noh JH, Sohn TS, Kim S. Surgical outcome after incomplete endoscopic submucosal dissection of gastric cancer. Br J Surg. 2011 Jan;98(1):73-8.

65 Lee S, Choi KD, Han M, Na HK, Ahn JY, Jung $\mathrm{KW}$, et al. Long-term outcomes of endoscopic submucosal dissection versus surgery in early gastric cancer meeting expanded indication including undifferentiated-type tumors: a criteria-based analysis. Gastric Cancer. 2018 May;21(3):490-9.

66 Maehara Y, Oshiro T, Endo K, Baba H, Oda $\mathrm{S}$, Ichiyoshi $\mathrm{Y}$, et al. Clinical significance of occult micrometastasis lymph nodes from $\mathrm{pa}$ tients with early gastric cancer who died of recurrence. Surgery. 1996 Apr;119(4):397402 . 
67 Saito H, Osaki T, Murakami D, Sakamoto $\mathrm{T}$, Kanaji S, Ohro S, et al. Recurrence in early gastric cancer-presence of micrometastasis in lymph node of node negative early gastric cancer patient with recurrence. Hepatogastroenterology. 2007 Mar;54(74): $620-4$.

68 Fujita J, Takahashi M, Urushihara T, Tanabe K, Kodera Y, Yumiba T, et al. Assessment of postoperative quality of life following pylorus-preserving gastrectomy and Billroth-I distal gastrectomy in gastric cancer patients: results of the nationwide postgastrectomy syndrome assessment study. Gastric Cancer. 2016 Jan;19(1):302-11.
69 Takiguchi N, Takahashi M, Ikeda M, Inagawa S, Ueda S, Nobuoka T, et al. Long-term quality-of-life comparison of total gastrectomy and proximal gastrectomy by postgastrectomy syndrome assessment scale (PGSAS-45): a nationwide multi-institutional study. Gastric Cancer. 2015 Apr;18(2):407-16.

70 Ryu KW, Eom BW, Nam BH, Lee JH, Kook MC, Choi IJ, et al. Is the sentinel node biopsy clinically applicable for limited lymphadenectomy and modified gastric resection in gastric cancer? A meta-analysis of feasibility studies. J Surg Oncol. 2011 Nov;104(6):578-84.

71 Nunobe S, Hiki N, Gotoda T, Murao T, Haruma K, Matsumoto H, et al. Successful appli- cation of laparoscopic and endoscopic cooperative surgery (LECS) for a lateral-spreading mucosal gastric cancer. Gastric Cancer. 2012 Jul;15(3):338-42.

72 InoueH,IkedaH,Hosoya T, Yoshida A, OnimaruM,SuzukiM, etal.Endoscopicmucosal resection, endoscopicsubmucosaldissection, andbeyond: full-layer resection for gastric cancer with nonexposure technique (CLEAN-NET). Surg Oncol Clin N Am. 2012 Jan;21(1):129-40.

73 Aoki M, Tokioka S, Narabayashi K, Hakoda A, Inoue Y, Yorifuji N, et al. Laparoscopic and endoscopic cooperative surgery for intra-mucosal gastric carcinoma adjacent to the ulcer scars. World J Surg Oncol. 2018 Mar;16(1):53. 